\title{
An Abrupt Transition to an Intergranular Failure Mode in the Near-Threshold Fatigue Crack Growth Regime in Ni- Based Superalloys
}

J. Telesman, T.M. Smith, T.P. Gabb and A.J. Ring

NASA Glenn Research Center

Cleveland, OH, USA

Support provided by NASA's Advanced Air Transport Technology

(AATT) Project Office (ARMD) 


\section{Motivation}

- Most of cyclic fatigue crack growth (FCG) life occurs in the near threshold regime; limited research published in superalloys.

- Recent discovery of sudden transition to an intergranular failure mode in the near-threshold cyclic FCG regime - need to understand the underlying science.

- Surprising, since intergranular failure is typically associated with increase in FCG and not slow FCG rates of the threshold regime.

- What causes the transition in the failure mode? Detailed look at crack tip behavior.

- What are the crack driving forces for intergranular failure?

- Mixed mode failure typically observed in the Paris FCG regime - what does this actually mean and how does it effect FCG propagation rates? 


\section{Experimental}

Material: Low Solvus High Refractory (LSHR) and ME3 P/M nickel-base disk alloys

\begin{tabular}{|c|c|c|c|c|c|c|c|c|c|c|c|c|}
\hline Alloy & $\mathrm{Ni}$ & $\mathrm{Cr}$ & $\mathrm{Co}$ & $\mathrm{Mo}$ & $\mathrm{W}$ & $\mathrm{Nb}$ & $\mathrm{Ta}$ & $\mathrm{Al}$ & $\mathrm{Ti}$ & $\mathrm{Zr}$ & $\mathrm{B}$ & $\mathrm{C}$ \\
\hline ME3 & Bal. & 13 & 21 & 3.7 & 2.1 & 0.8 & 2.4 & 3.4 & 3.8 & 0.05 & 0.02 & 0.05 \\
\hline LSHR & Bal. & 12.5 & 20.4 & 2.7 & 4.3 & 1.5 & 1.5 & 3.5 & 3.5 & 0.05 & 0.03 & 0.045 \\
\hline
\end{tabular}

- Supersolvus Grain Size: LSHR - ASTM 8; ME3 - ASTM 7

FCG Testing:

- Mostly at $704^{\circ} \mathrm{C}$; selected specimens at $538^{\circ} \mathrm{C}$ and $760^{\circ} \mathrm{C}$; $R$ ratio of 0.05 ; few at 0.5

- Test frequency range: from $0.333 \mathrm{~Hz}$ to $30 \mathrm{~Hz}$ ( majority at $0.333 \mathrm{~Hz}$ )

- Environment: air with additional selected vacuum tests

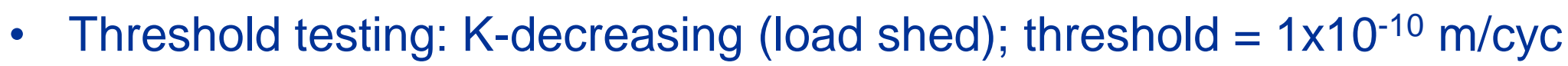

- Near threshold testing: constant load tests started at near-threshold $\Delta \mathrm{K}$ values

- Paris regime: Constant $\Delta \mathrm{K}=25 \mathrm{MPa} \sqrt{\mathrm{m}}$ at $0.333 \mathrm{~Hz}, 2 \mathrm{~Hz}$ and $10 \mathrm{~Hz}$

- Specimen geometry: Surface flaw $\left(K_{B}\right.$ bar) 


\section{Near Threshold Crossover Effect}
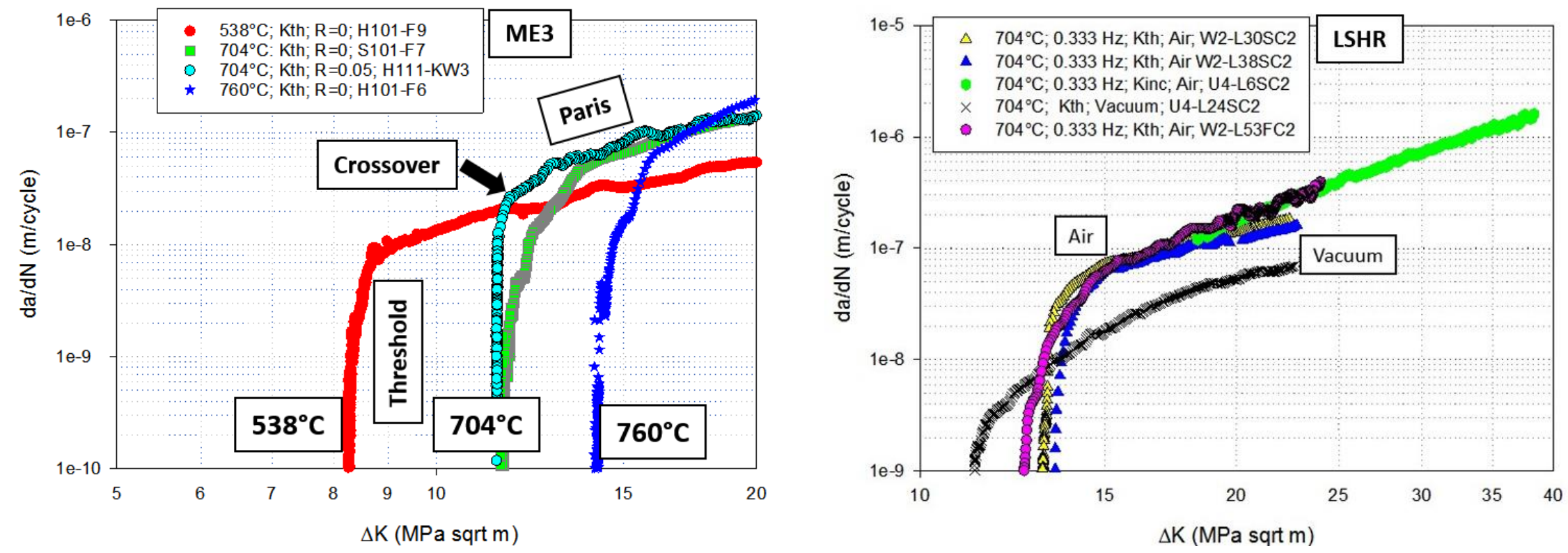

- Higher FCG rates in the Paris regime at higher temperatures, air vs vacuum.

- Higher resistance to FCG in the near-threshold region.

- Limited literature on the subject, crossover attributed to increase in oxide induced crack closure 
Abrupt Change in Failure Mode at the onset of Near-Threshold Regime; LSHR
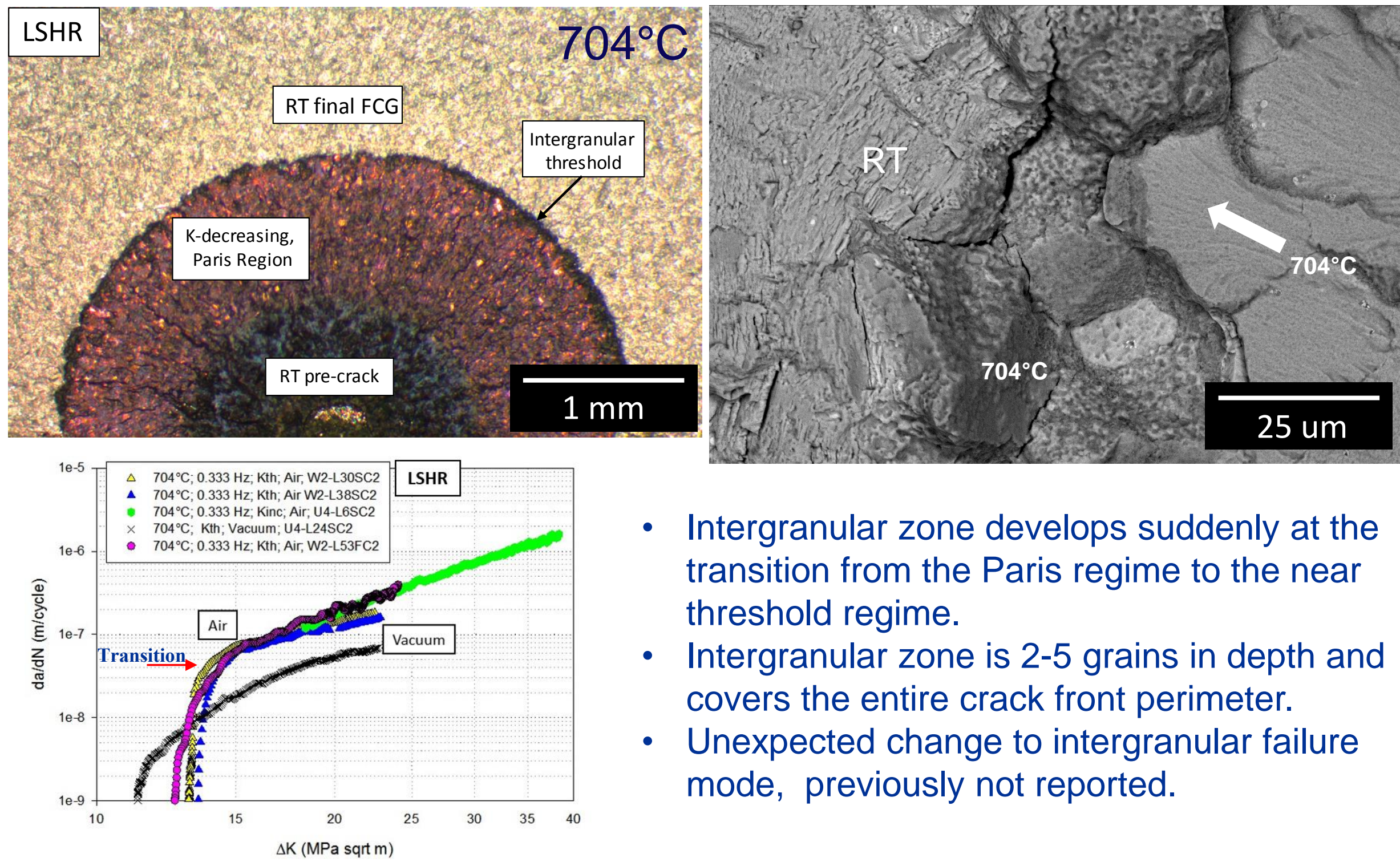

- Intergranular zone develops suddenly at the transition from the Paris regime to the near threshold regime.

- Intergranular zone is 2-5 grains in depth and covers the entire crack front perimeter.

- Unexpected change to intergranular failure mode, previously not reported. 


\section{ME3 - Near Threshold FCG Abrupt Failure Mode Transition}

$704^{\circ} \mathrm{C}$; $0.333 \mathrm{~Hz}$; K-decreasing threshold test
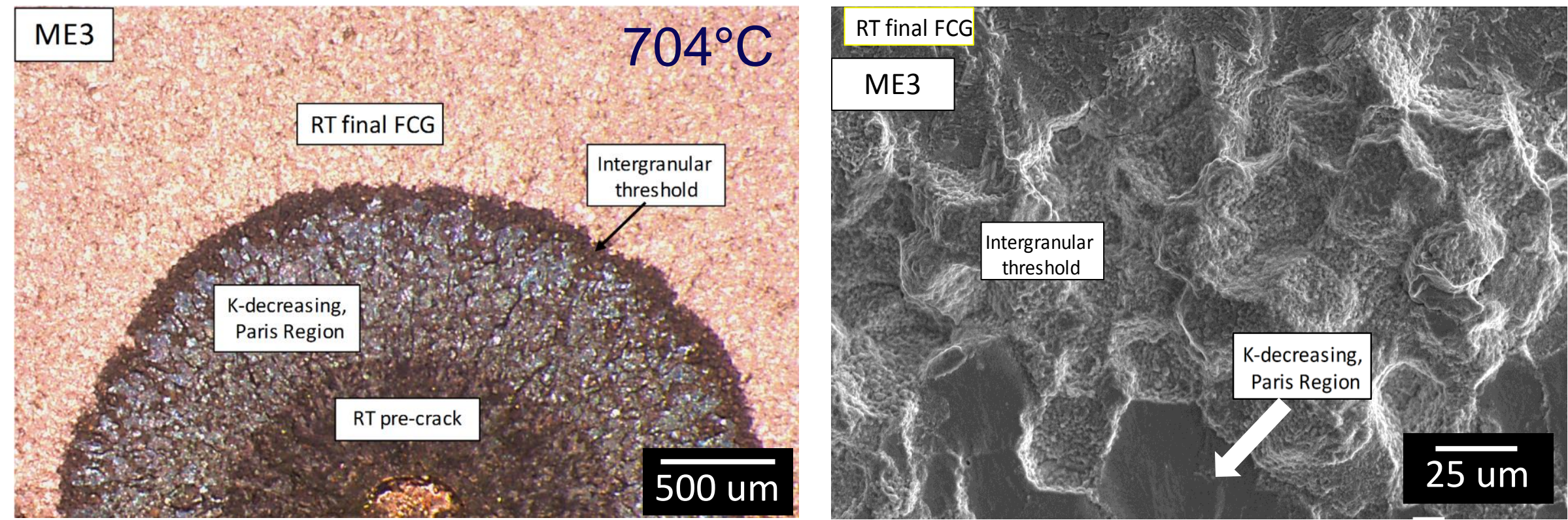

- Abrupt failure mode transition also occurs during threshold tests in ME3 


\section{LSHR K-Increasing FCG Tests: Abrupt Failure Mode Transition}
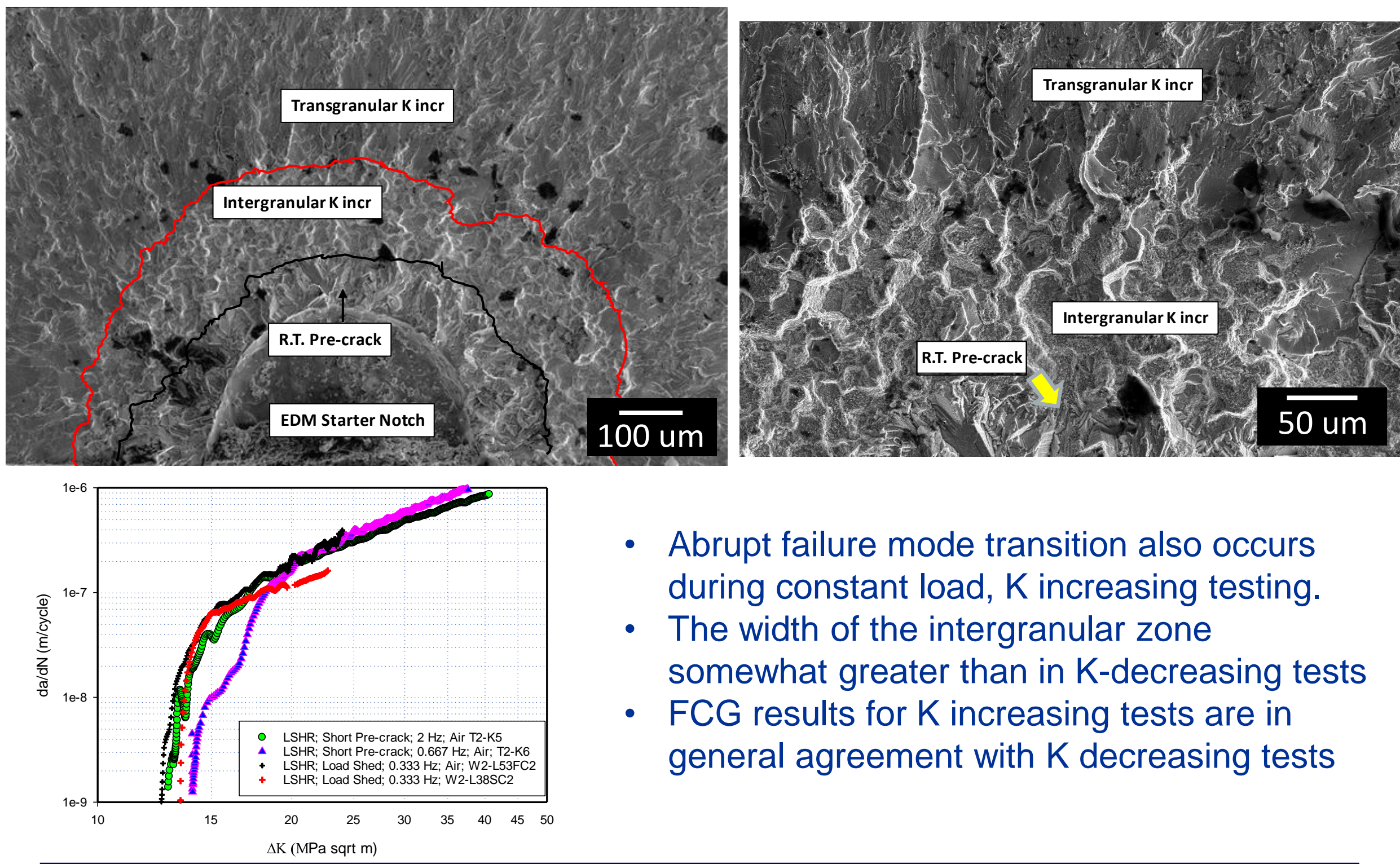

- Abrupt failure mode transition also occurs during constant load, $\mathrm{K}$ increasing testing.

- The width of the intergranular zone somewhat greater than in K-decreasing tests

- $F C G$ results for $K$ increasing tests are in general agreement with $\mathrm{K}$ decreasing tests 


\section{Existence of Failure Mode Transition Depends on Test Conditions}

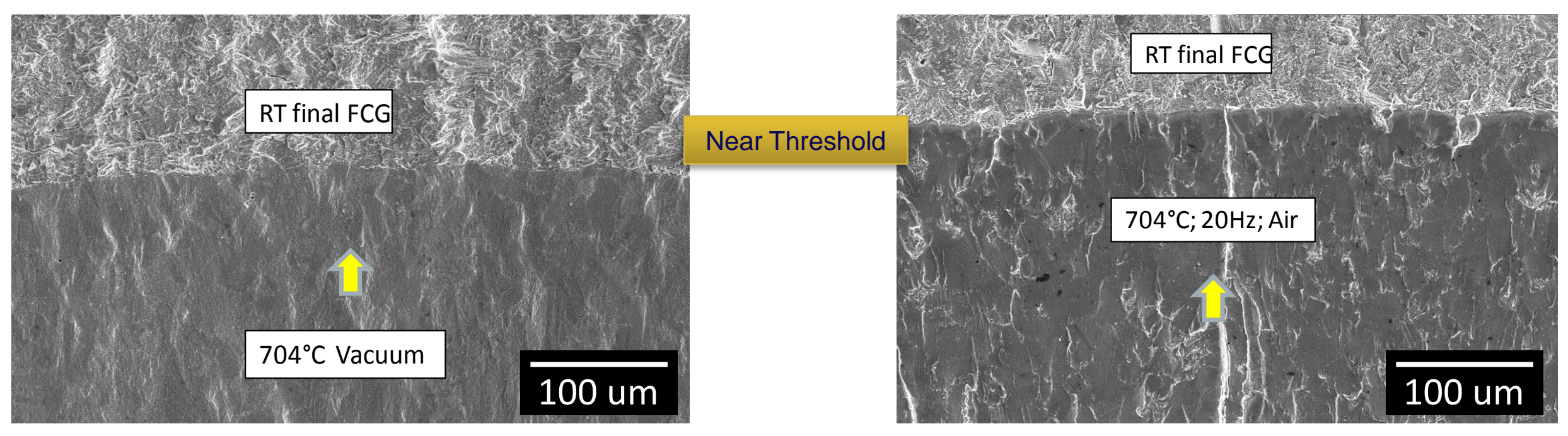

- No failure mode transition for tests performed in vacuum, at high frequencies or lower temperatures.

- Failure mode transition phenomenon dependent on environmental interactions.

- Kinetic requirements need to be satisfied for appropriate reactions to take place to cause failure mode transition. 
Variation in Oxide Thickness for the Two Failure Modes

Near Threshold, Intergranular

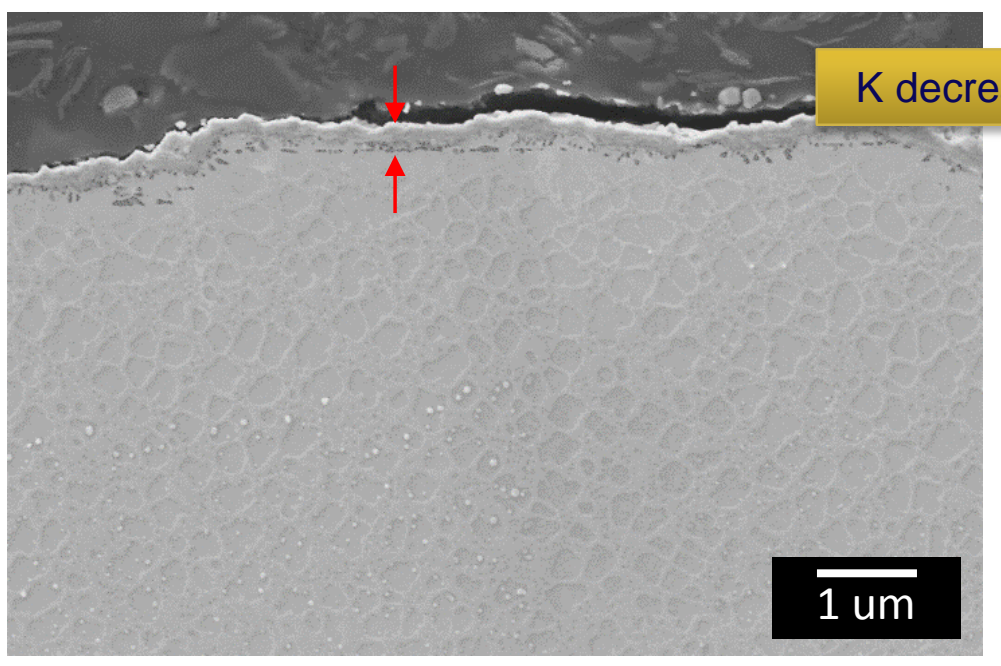

Average: $260 \mathrm{~nm}$

95\% Confidence interval: $34 \mathrm{~nm}$

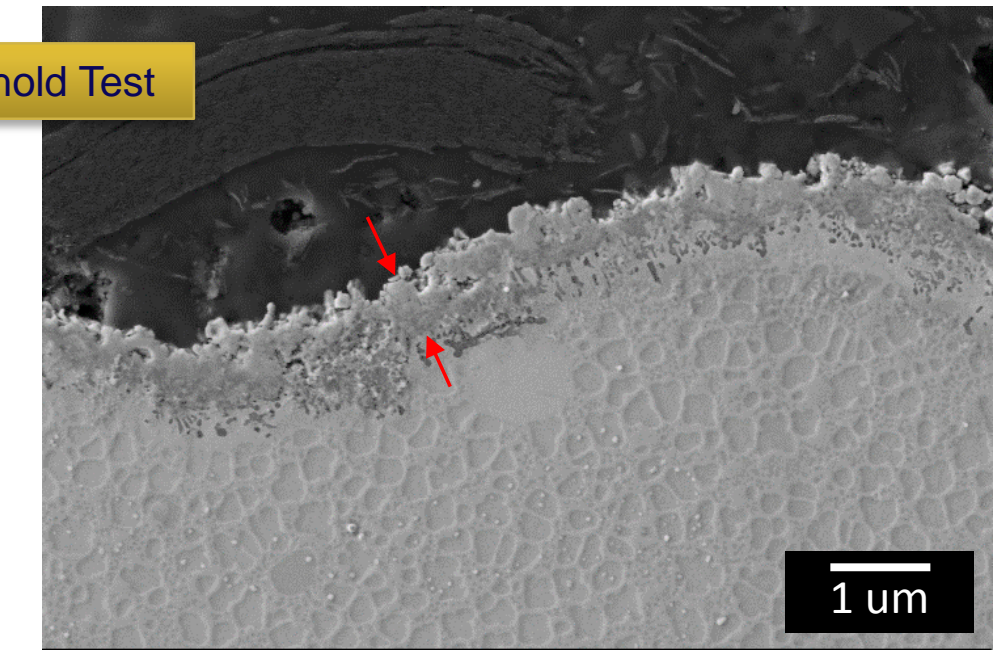

Average: $636 \mathrm{~nm}$

95\% Confidence interval: $124 \mathrm{~nm}$

- Oxide formation accelerated by presence of grain boundaries.

- Intergranular oxide thickness $>2 X$ transgranular layer.

- Change in oxide thickness increases crack closure, partly responsible for the crossover effect (does not explain why failure mode transition takes place). 


\section{What Crack Driving Force is Most Suitable for Correlating Intergranular Near Threshold Failure Mode?}

- Transgranular FCG process governed by cyclic plasticity $\rightarrow \Delta \mathrm{K}$ parameter

- Intergranular crack growth during hold time tests $\rightarrow \mathrm{K}_{\max }$ parameter

- Cyclic crack advancement through oxidized grain boundaries $\rightarrow$ ?
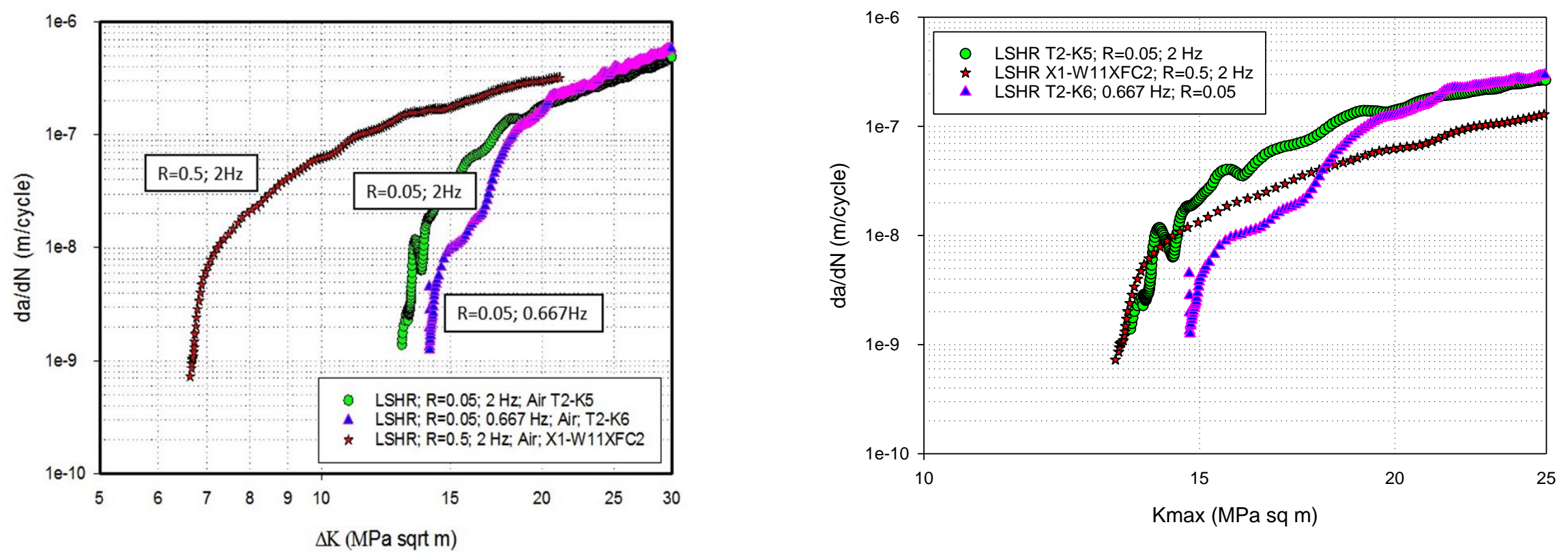

- Difficult to visualize cyclic plasticity governing FCG of oxidized grain boundaries.

- Crack growth in embrittled materials is governed by Kmax.

- Kmax parameter does a better job in correlating near threshold regime.

- Crack advancement through oxide micro-cracking process. 


\section{Interrupted K-decreasing Threshold Test}

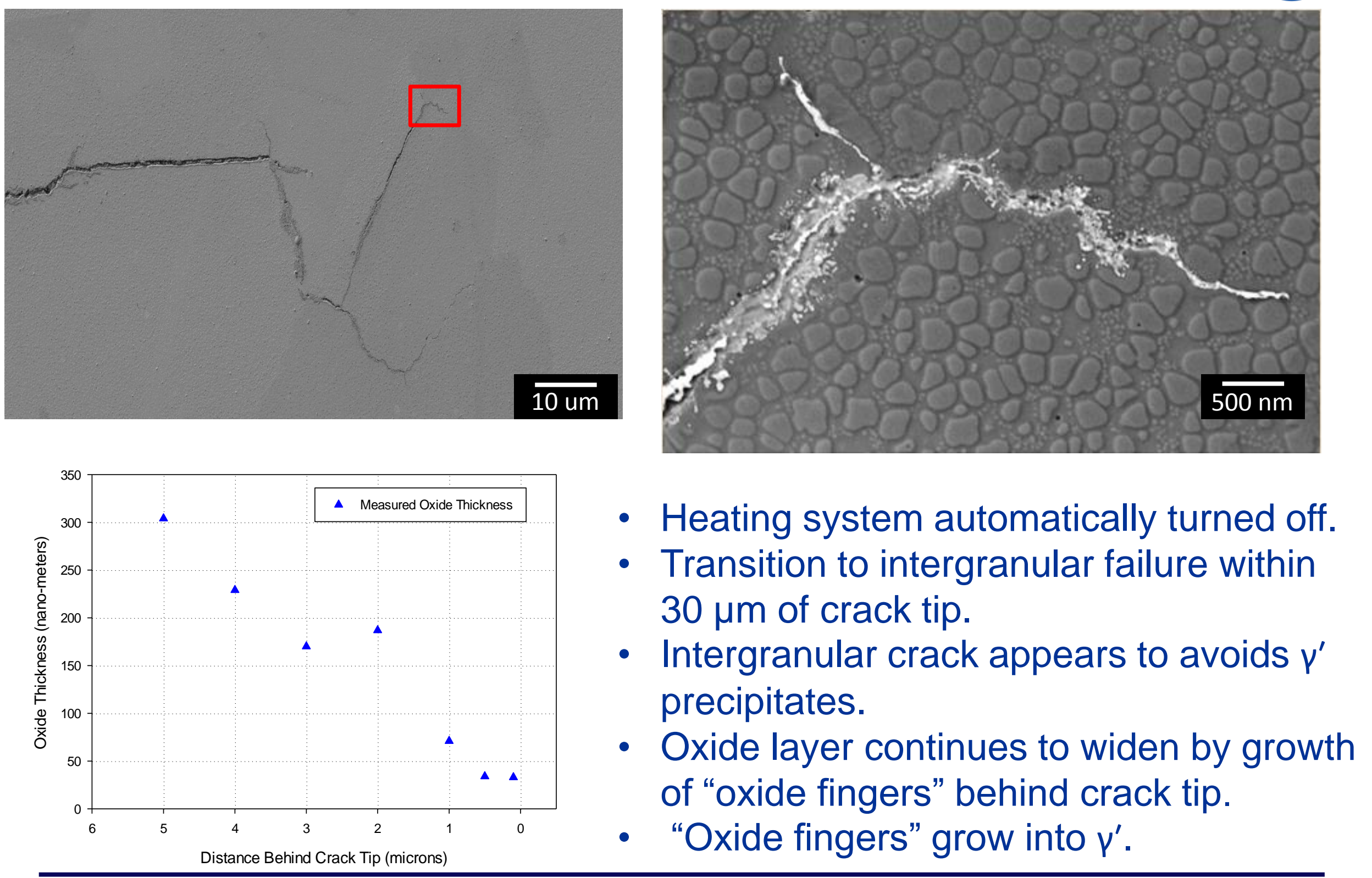




\section{Scanning Transmission Electron Microscopy (STEM) Analysis of Crack Oxidation}
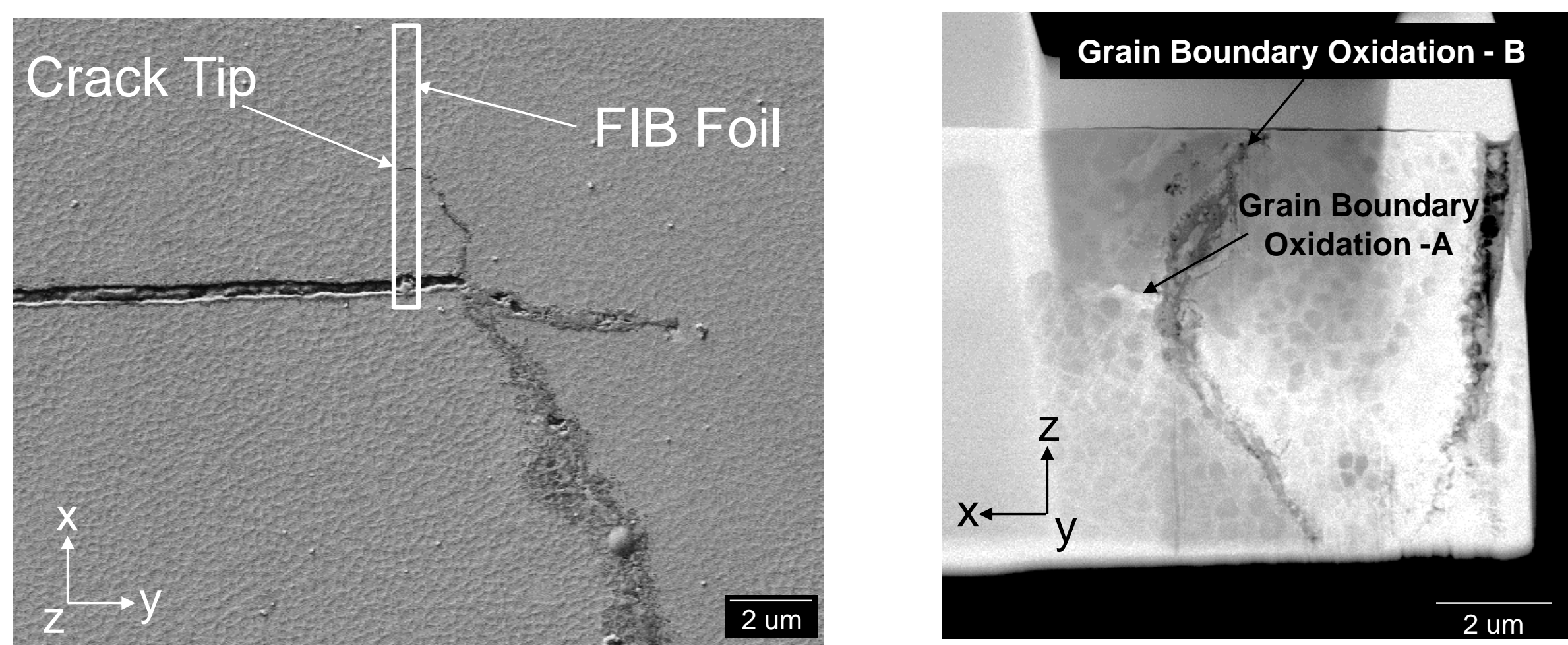

STEM FIB foil was extracted at a crack tip in order to better understand what causes the transition in the failure mode. 


\section{STEM EDS of Crack Tip Oxidation - Region A}

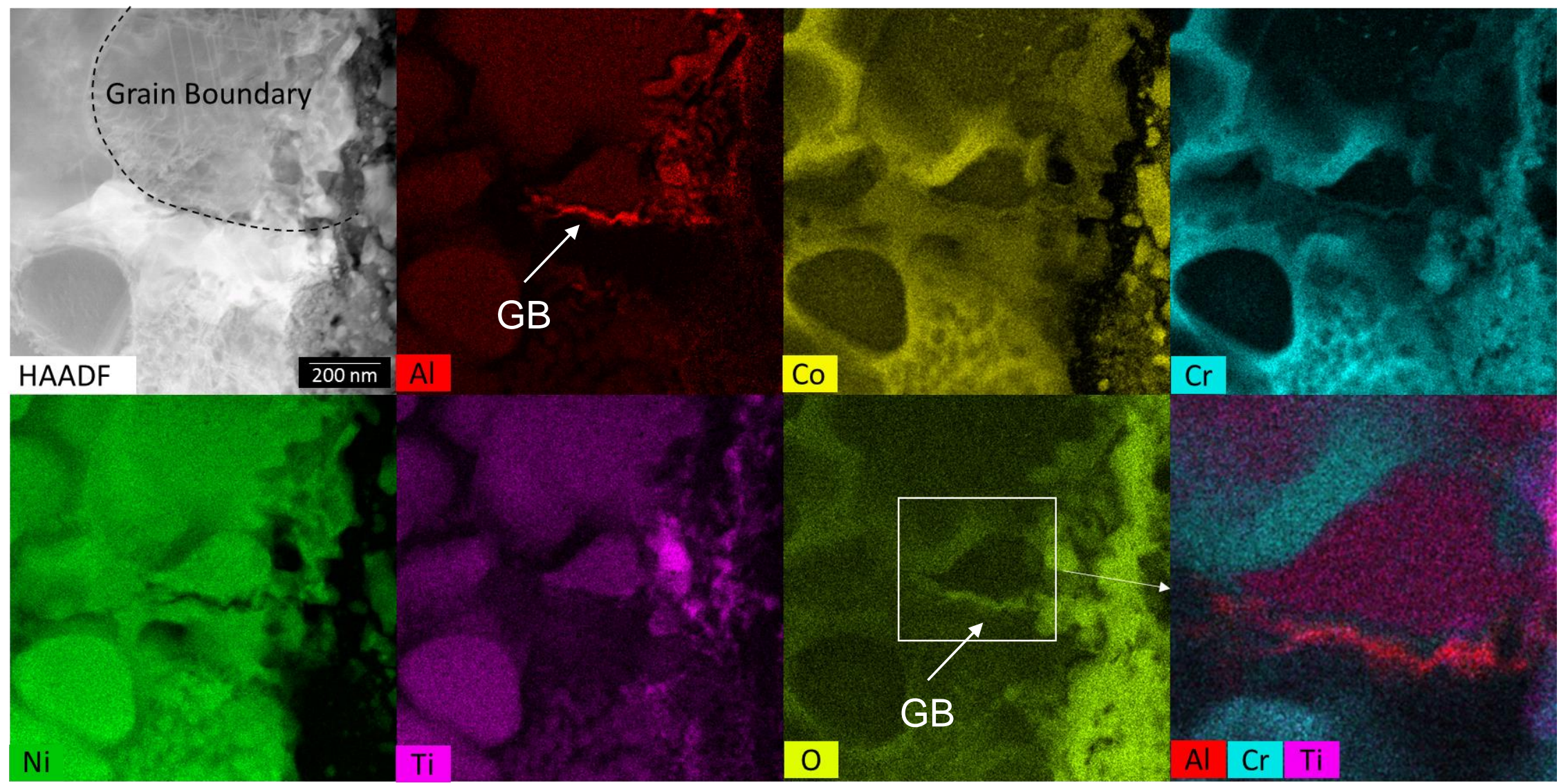

- High resolution STEM-EDS maps reveal Al-oxidation along a grain boundary.

- The composite map reveals a layer of $y$ between the Al-oxide and the Y' precipitate. 


\section{STEM EDS of Crack Tip Oxidation - Region A}
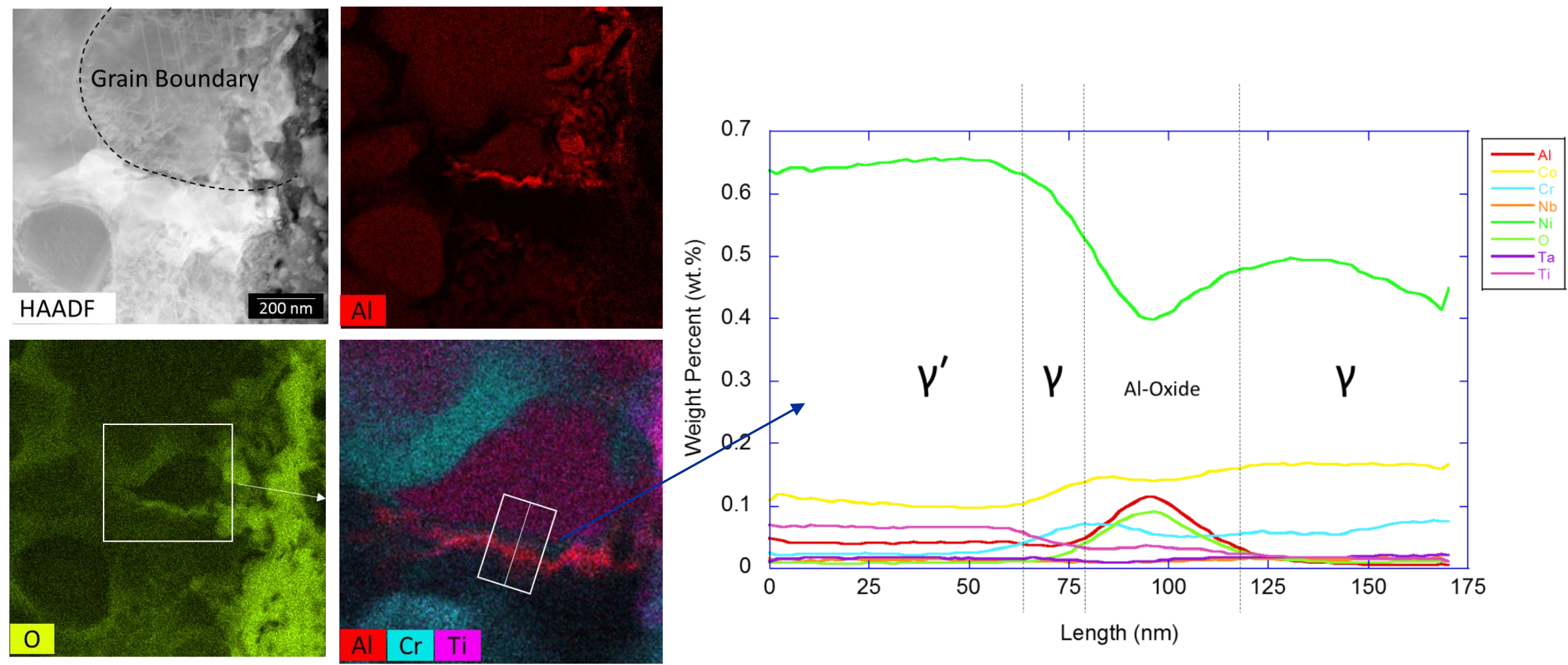

- High resolution STEM-EDS maps reveal Al-oxidation along a grain boundary.

- The composite map reveals a layer of $y$ between the Al-oxide and the Y' precipitate. 


\section{STEM EDS of Crack Tip Oxidation - Region B}
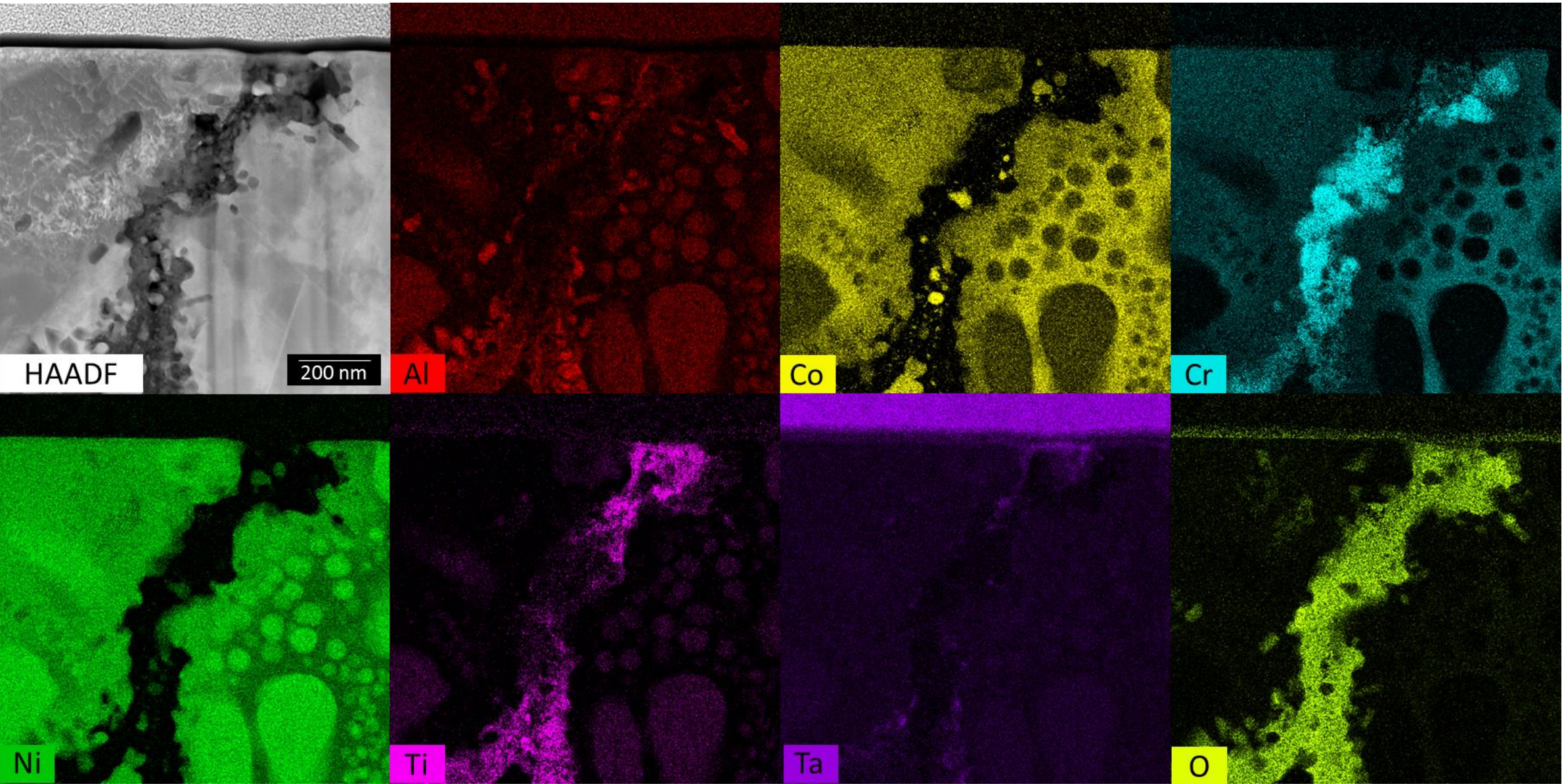

- High resolution STEM-EDS maps reveal Ti and $\mathrm{Cr}$ oxidation forming along a grain boundary after the initial Al-oxide formation.

- The composite map reveals the presence of Ti or $\mathrm{Cr}$ oxidation is dictated by the surrounding microstructure 


\section{STEM EDS of Crack Tip Oxidation - Region B}

\section{(a)}

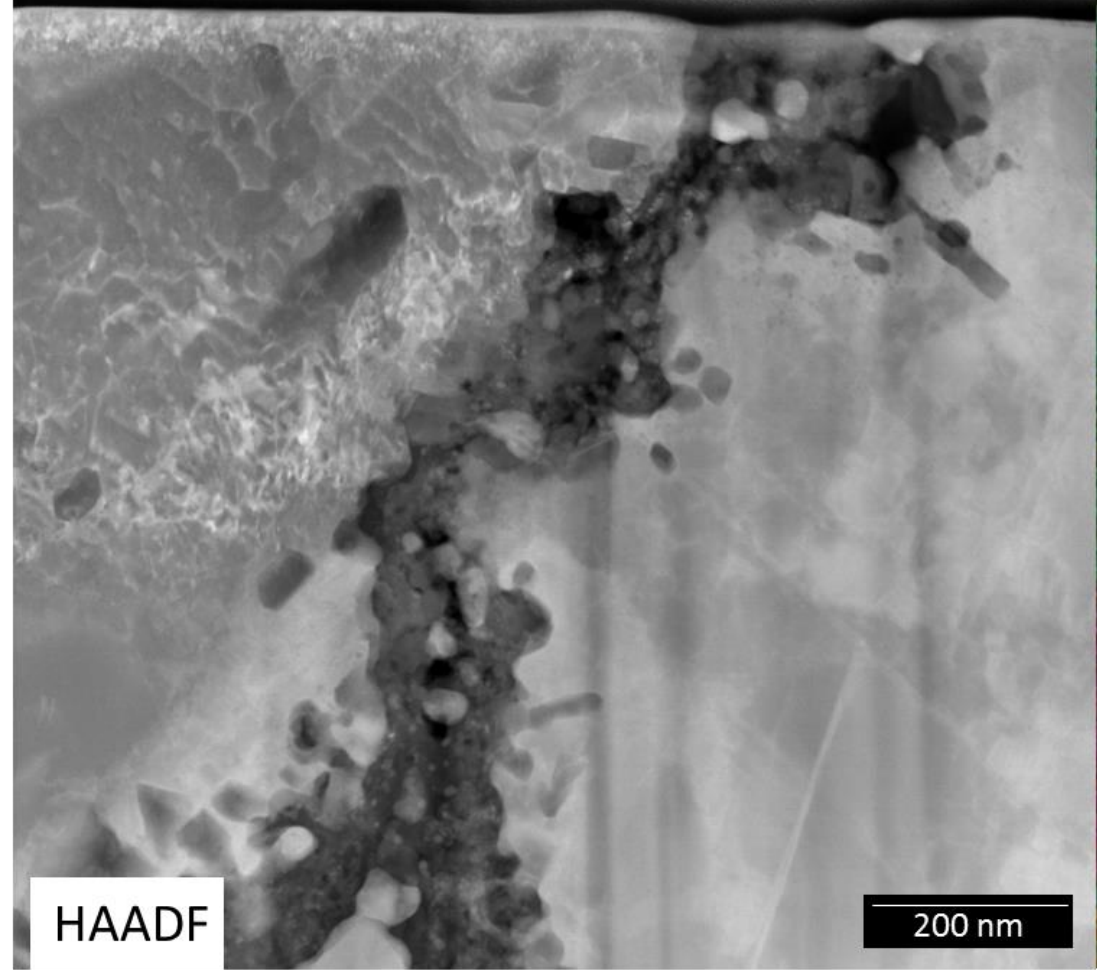

(b)

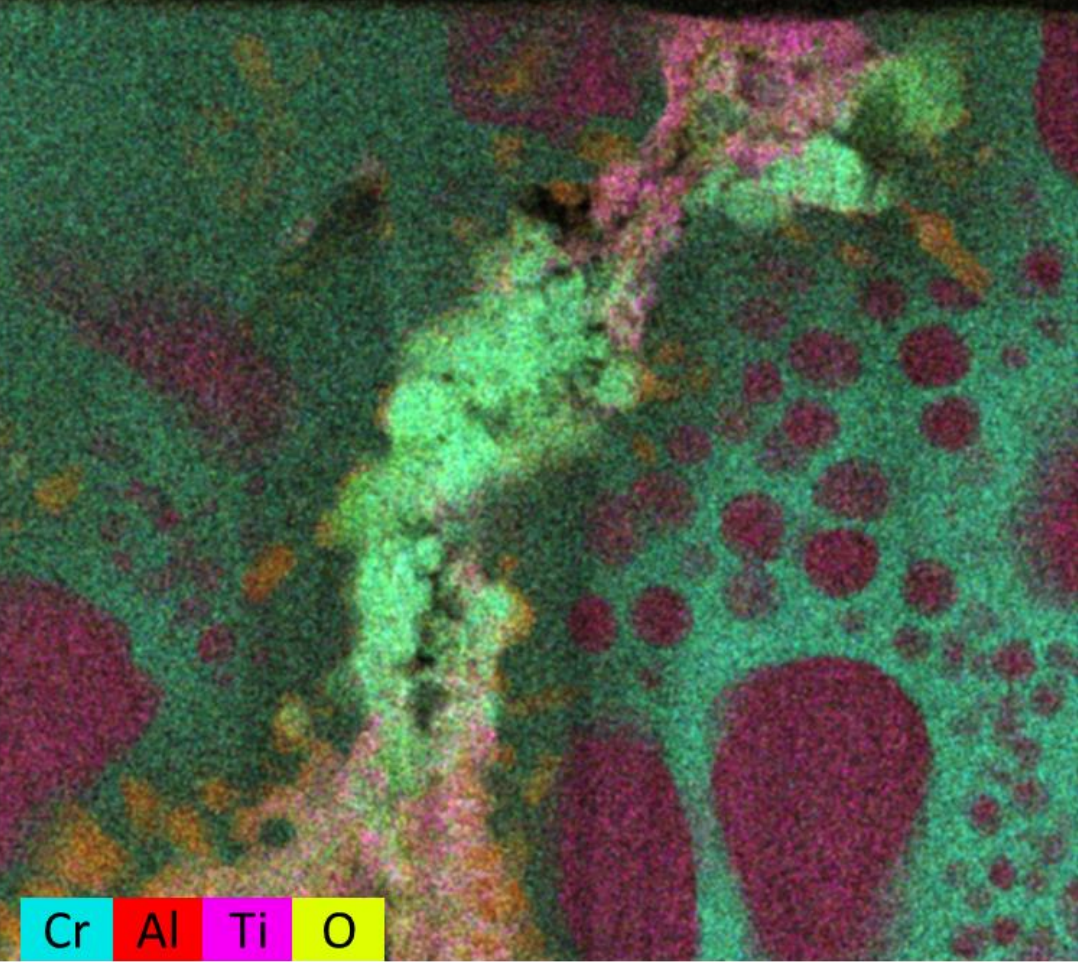

- High resolution STEM-EDS maps reveal Ti and Cr oxidation forming along a grain boundary after the initial Al-oxide formation.

- The composite map reveals the presence of $\mathrm{Ti}$ or $\mathrm{Cr}$ oxidation is dictated by the surrounding microstructure 
Role of Intergranular Failure on Cyclic FCG in the Paris Regime

- Mixed mode failure mode commonly encountered in the Paris regime at $\mathrm{T}>600^{\circ} \mathrm{C}$

- What is the impact of intergranular failure component on FCG in Paris regime?
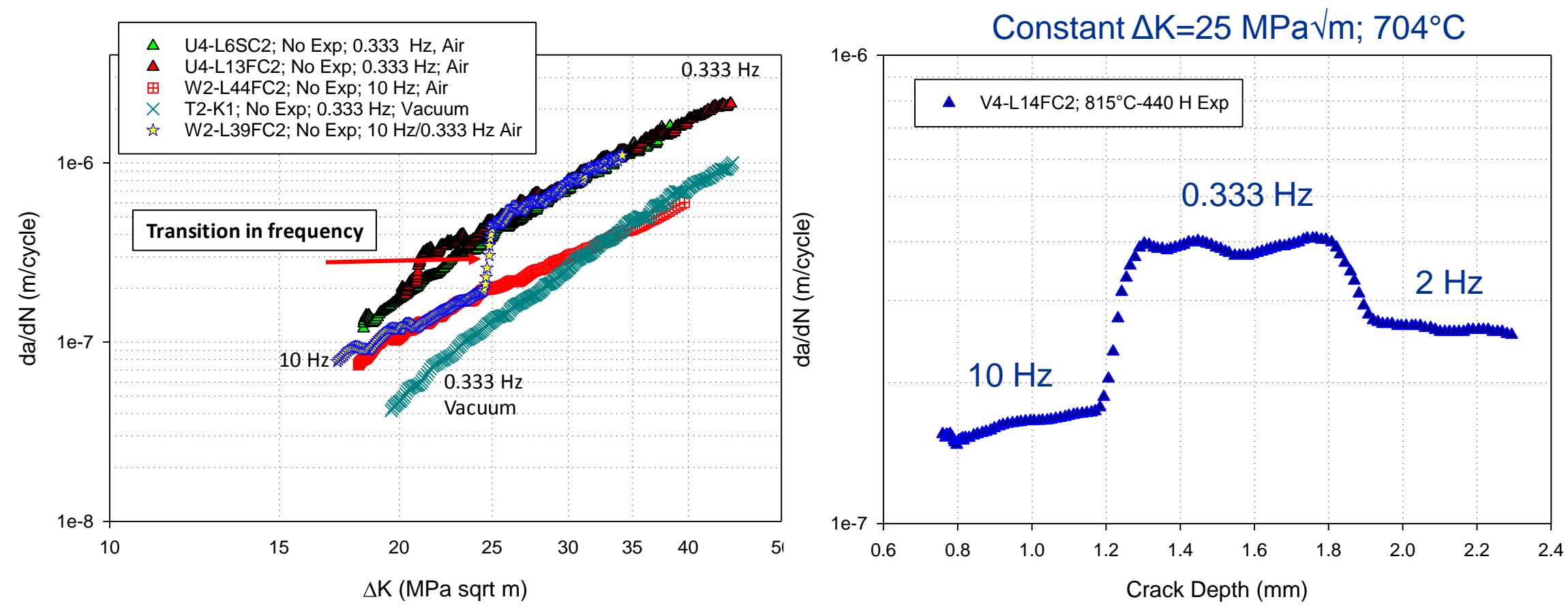

- Decreasing frequency increases FCG rates and intergranular failure content 
Percent of Intergranular Content Quantified for Varied Heat Treatments at Different Test Frequencies

Heat treatment resistant to cyclic FCG integranular failure
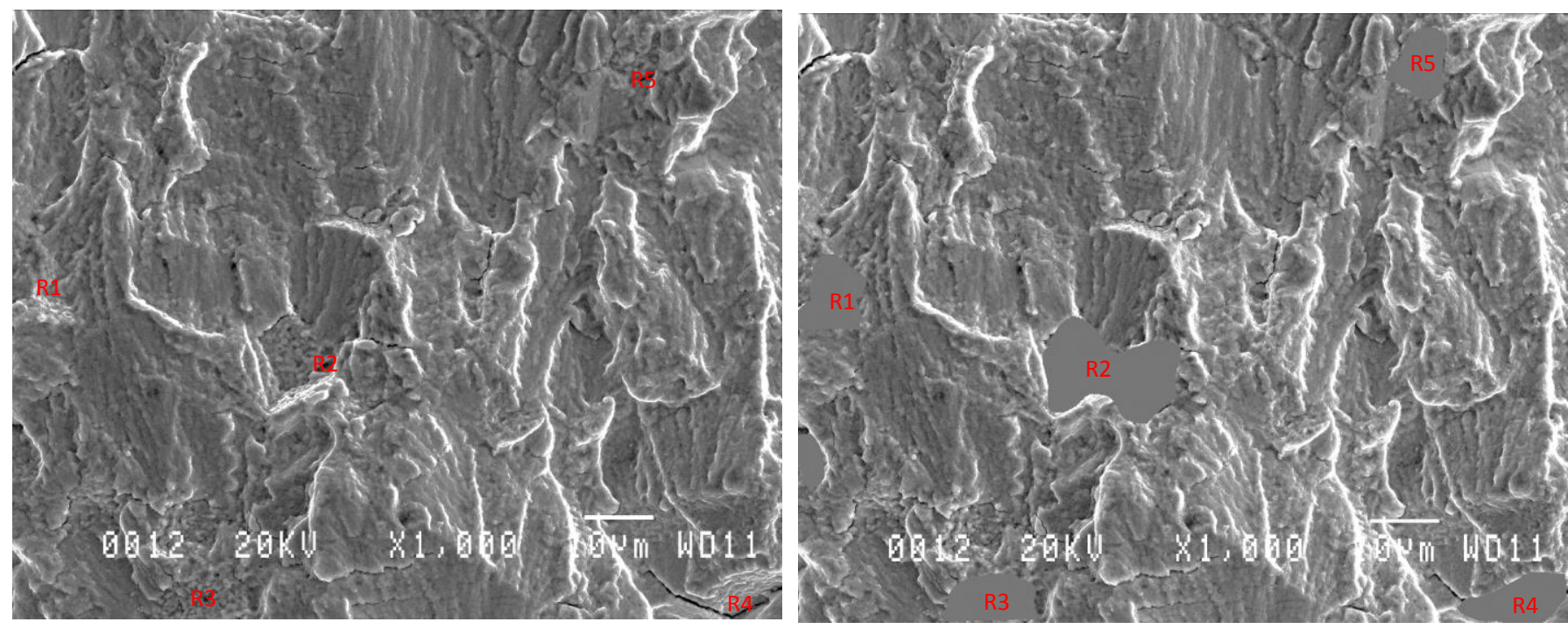

LSHR: $704^{\circ} \mathrm{C}$; $\Delta \mathrm{K}=25 \mathrm{MPa} \sqrt{\mathrm{m}}$

$\approx 5 \% \mathrm{IG}$;

$0.333 \mathrm{~Hz}$

Heat treatment prone to cyclic FCG integranular failure
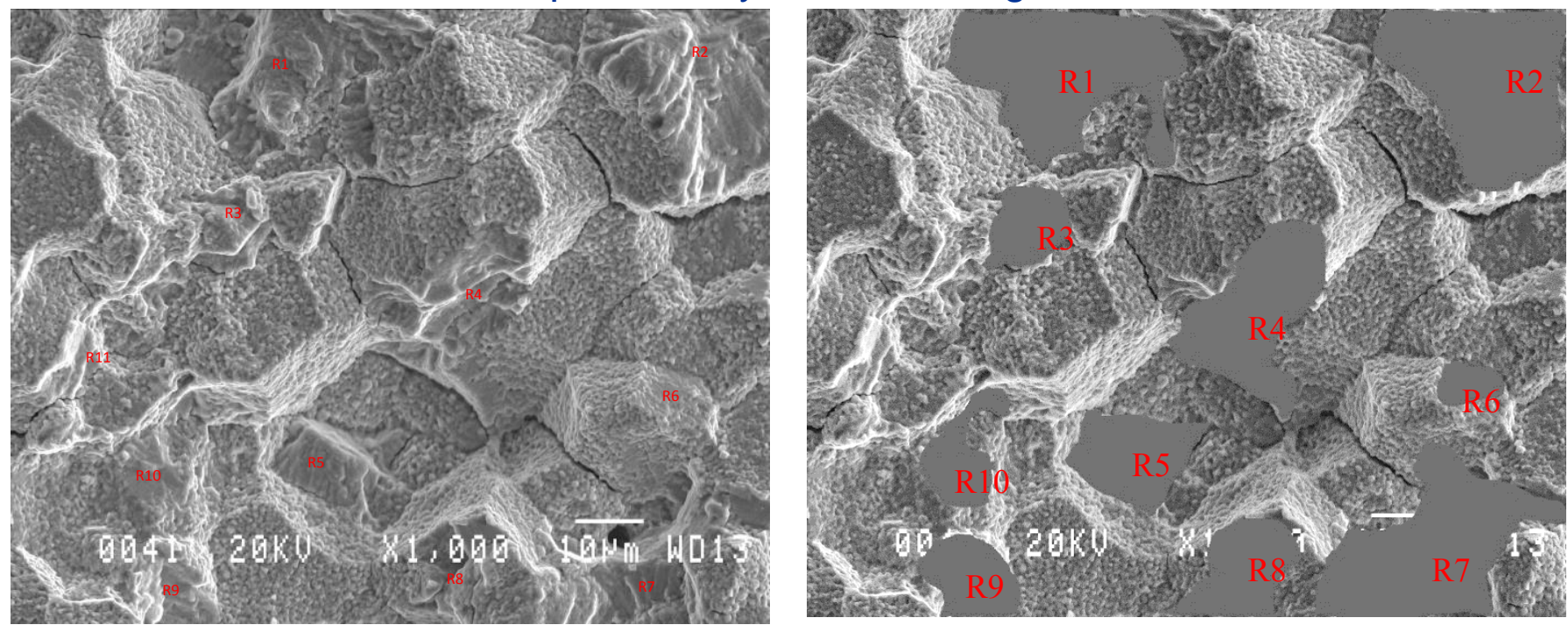

LSHR: $704^{\circ} \mathrm{C}$; $\Delta \mathrm{K}=25 \mathrm{MPa} \sqrt{\mathrm{m}}$

$\approx 72 \% \mathrm{IG}$;

$0.333 \mathrm{~Hz}$ 
Relationship Between Percentage of Intergranular Failure and Cyclic FCG Rates - Paris Regime

Rule of Mixtures FCG Predictions
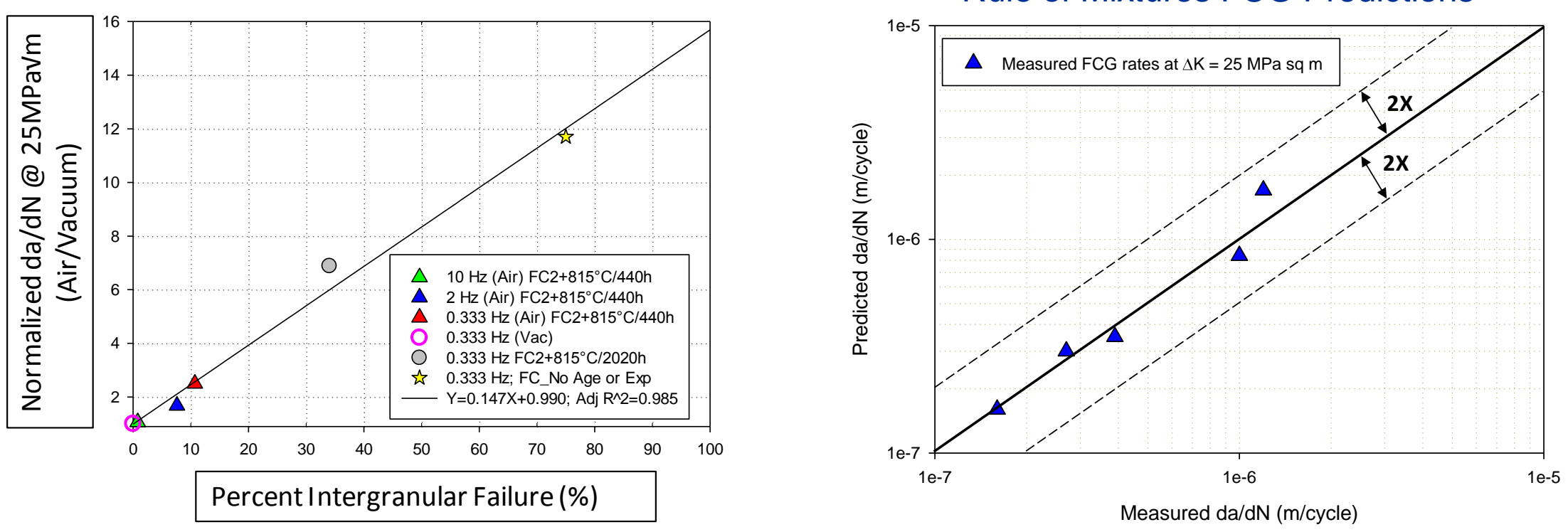

- Intergranular failure content dominant factor in Paris regime cyclic FCG resistance.

- $10 \%$ integranular failure content increases FCG rates by $\approx 2 x$

- Linear relationship between intergranular failure content and FCG rates.

- The linearity of the relationship enables use of Rule of Mixtures to predict FCG

- Once GB's transition to intergranular failure, their contribution to increasing FCG is the same without regard to their previous ability to resist intergranular failure. 


\section{Conclusions}

- Unexpected failure mode transition to intergranular failure in the nearthreshold FCG regime documented and characterized for LSHR and ME3 superalloys

- Formation of stable $\mathrm{Al}$ and $\mathrm{Cr}$ oxides protects the crack tip region from early formation of deleterious $\mathrm{Ni}$ oxides and is thought to slow down crack growth

- Failure mode transition proposed to occur when the rate of FCG exceeds the rate at which protective stable oxides can form.

- In the near-threshold regime crack advances through an oxide microcracking process which is mostly governed by Kmax parameter.

- In contrast, for the Paris regime the percentage of intergranular cracking in the mixed mode failure dominates FCG rates in comparison to transgranular failure. 


\section{Acknowledgments}

\section{Questions?}

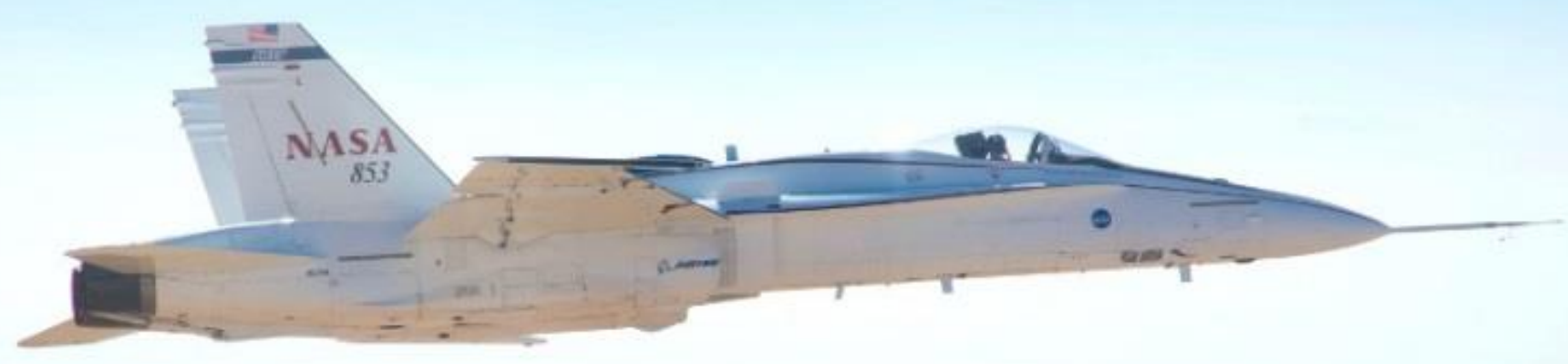

- CEMAS (OSU)

- Anita Garg

- Laura Evans

- Joy Buehler 


\section{Backup}


Table II. Comparison of Intergranular Band Width with Near-Threshold Region Crack Growth Distance at $704{ }^{\circ} \mathrm{C}$, Tested at $R=0.05$

\begin{tabular}{|c|c|c|c|c|c|}
\hline Alloy/Specimen & Test Type & Frequency $(\mathrm{Hz})$ & $\begin{array}{l}\text { Crack Length Distance } \\
\text { to/from } 4 \times 10^{-8} \mathrm{~m} / \\
\text { Cycle to } / \text { from } \\
\text { Threshold }(\mu \mathrm{m})\end{array}$ & $\begin{array}{c}\text { Average Intergranular } \\
\text { Band Width } \\
\text { (Five Measurements, } \\
\mu \mathrm{m})\end{array}$ & $\begin{array}{l}K_{\max } \text { at Failure } \\
\text { Mode Transition } \\
\left(\mathrm{MPa} \mathrm{m}{ }^{1 / 2}\right)\end{array}$ \\
\hline LSHR/W2-L30SC2 & load shed & 0.333 & 75 & 72 & 14.5 \\
\hline LSHR/W2-L38SC2 & load shed & 0.333 & 75 & 82 & 14.5 \\
\hline LSHR/W2-L53FC2 & load shed & 0.333 & 187 & 170 & 15.5 \\
\hline $\mathrm{ME} 3 / \mathrm{H} 111-\mathrm{KW} 3$ & load shed & 0.333 & 110 & 105 & 13 \\
\hline ME3/H111-KR3 & load shed & 0.333 & 120 & 110 & 13.8 \\
\hline LSHR/T2-K5 & $\begin{array}{l}\text { constant load/ } \\
\text { short precrack }\end{array}$ & 2 & 137 & 131 & 15.8 \\
\hline LSHR/T2-K 6 & $\begin{array}{l}\text { constant load/ } \\
\text { short precrack }\end{array}$ & 0.667 & 205 & 222 & 18 \\
\hline
\end{tabular}




\section{Transgranular Crack Oxidation}
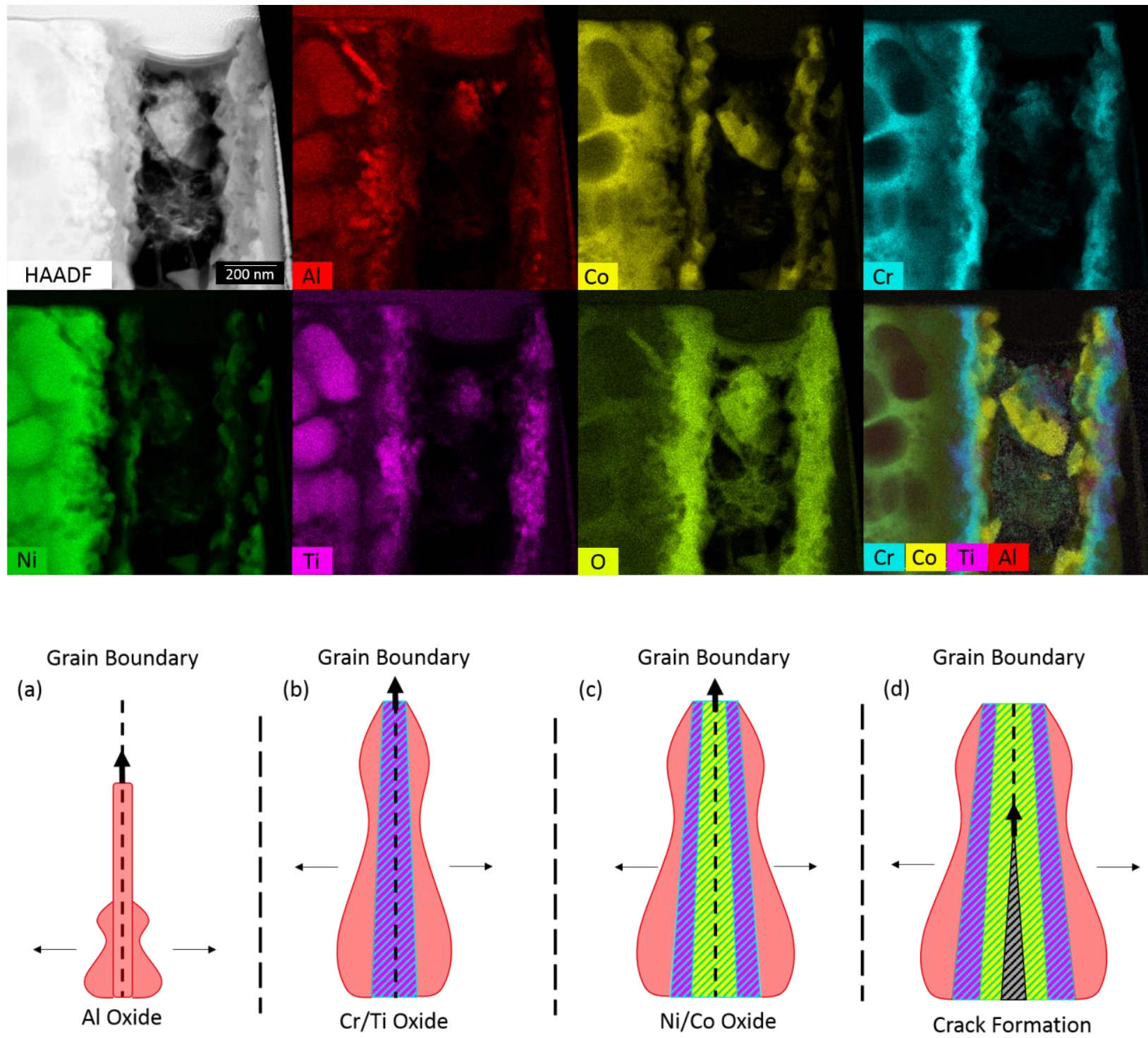


\section{Presence of Stacking Fault Segregation and Cottrell Atmospheres}

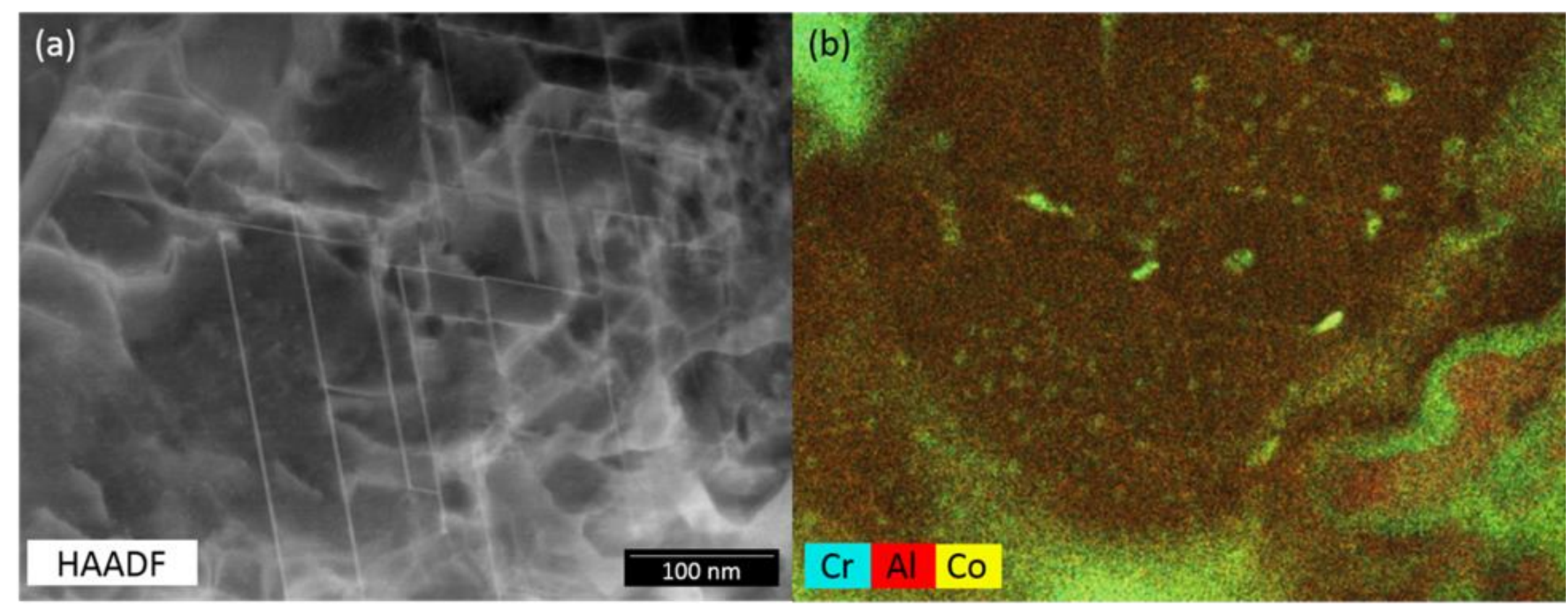

